水素化リチウムムアルシウムによる Vinylogous Ester の䍝元 (第 5 報1)

的場勝英, 宮林紀子, 山崎高応

富山大学薬学部》)

\title{
Reduction of Some Vinylogous Esters with Lithium Aluminum Hydride. V1)
}

\author{
Katsuhide Matoba, Noriko Miyabayashi, and Takao Yamazaki \\ Faculty of Pharmaceutical Sciences, University of Toyama?
}

(Received January 20, 1973)

\begin{abstract}
With excess lithium aluminum hydride, 2-methyl-3-methoxy-2-cyclopentenone. (III), 2-ethyl-3-methoxy-2-cyclopentenone (IV), and 2,5-dimethyl-3-methoxy-2-cyclopentenone (VI) were reduced to the corresponding allyl alcohols, 2-methyl-2-cyclopentenol (Xa), 2-ethyl-2-cyclopentenol (XIa), and 2,5-dimethyl-2-cyclopentenol (XIIa), respectively. On the other hand, 2,4-dimethyl-3-methoxy-2-cyclopentenone $(V)$ was reduced to 2,4dimethyl-2-cyclopentenol (XIVa), 2,5-dimethyl-2-cyclopentenone $\left(\mathrm{XIII}_{(\mathrm{\eta}) \mathrm{c}}\right)$, and 2,4dimethyl-3-methoxy-2-cyclopentenol (XVc). Mechanism of this reduction and the substituent effect are described.
\end{abstract}

著者らは先に acutumine (I) の 5 員謤 vinylogous ester との関連において，モデル化合物として $\gamma$ 位ないし は $\delta$ 位に水酸基を有する 5 員環 vinylogous ester の水素化リチウムアルミニウム（以下 LAH と略す）による 還元について重点的㑢告してきた.1) その中で著者らは 6 員環 vinylogous estcr では全く見ることのできな

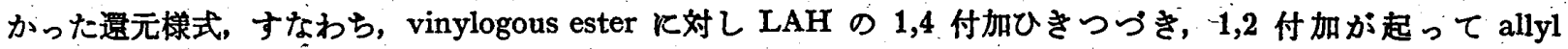
alcohol となる還元様式が 5 員環 vinylogous ester ではよく見かけられ，中でも $\alpha$ 位に $n$-butyl 基を有する 5 員瑟 vinylogous ester, 2-n-butyl-3-methoxy-2-cyclopentenone (II) ではこの様式による生成物が唯一の生成物 であることを見い出した.3) 今回このよ5な反応様式が $\alpha$ 位に $n$-butyl 基以外の alkyl 置換基を有する 5 員渨 vinylogous ester でも一般的に起るのかといら点を検討するため 2-methyl-3-methoxy-2-cyclopentenone (III) および 2-ethyl-3-methoxy-2-cyclopentenone (IV) とついて LAH 還元を行ないかつまた 5 員環 vinylogous ester の $\gamma$ 位あるいは $\delta$ 位に niethyl 基を入れる事により前報)で報告した水酸基以外の置換基効果を段階的に 検討する第 1 段階として，また併せて前報1) と述へた mechanism の正当性を再確認するために 2,4-dimethyl3-methoxy-2-cyclopentenone (V) およびその異性体である 2,5-dimethyl-3-methoxy-2-cyclopentenone (VI) K ついても LAH 僄元を行ない生成物を検討したのでここに報告する。

まず III一VI の合成について述べるＩII およびIVの直接の原料となる 2-alkylcyclopentane-1,3-dione (VIIa および VIIb) は Schick らの方法) そ従って合成しおのおのKジフメタンを加えることにより III お よび IVとした。 また V および VI の直接の原料となる 2,4-dimethylcyclopentane-1,3-dione (VIIc) は 2methylsuccinic acid を原料として Schick らの方法4) 準用して製した。 たたし反庆混合物を氷水に注いだす のを一夜放置しても析出した結晶はわずかであるがニトロメタン層と，水層を抽出するに用いたべンゼン層を合 しこれを水で抽出することにより VIIc の収量を上げることができた. 得られた diketone VIIc そジフンメタン を働かせて vinylogous ester の混合物を得た：カラム温度 $140^{\circ}$ のガスクロマトクラフィー（以下 GLC と略す） で面積比が 1:1.38 の 2 つの peak を示すことを確認しアルミナカラムクロマトグラフィーにより 2 つの物質

1）第 4 報：的場勝英，山畸高応，薬誌，92, 213 (1972).

2) Location: Gofuku, Toyama.

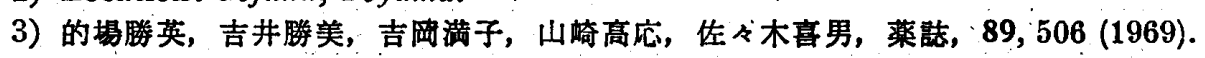

4) H. Schick, G. Lehmann, G. Hilgetag, Chein: Ber., 102, 3238 (1969). 


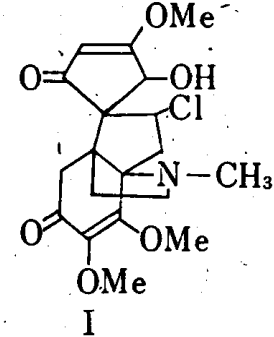

I<smiles>CO[C@H]1C[C@@H](C)[C@@H](OC)C1=O</smiles>

VI<smiles>COC(=O)c1c(Br)cccc1OC</smiles>

II<smiles>[R]C1CC(=O)C([R])C1=O</smiles>

VII a : $\mathrm{R}_{\alpha}=\mathrm{CH}_{3}, \mathrm{R}_{\gamma}=\mathrm{H}$

VII $b: \mathrm{R}_{\alpha}=\mathrm{C}_{2} \mathrm{H}_{5}, \mathrm{R}_{\gamma}=\mathrm{H}$

VII c : $\mathrm{R}_{u}=\mathrm{R}_{\gamma}=\mathrm{CH}_{3}$<smiles>CCC1=C(OC)CCC1=O</smiles>

III
V

Chart 1

を油状物として単離した．その中，先に溶離してくる物は核磁気共鳴スペクトル(以下 NMR と略す)で vinylic methyl が aliphatic methyl の付忖根の proton と homoallyl couplingi).することによって結合定数 $1.5 \mathrm{~Hz}$ の doublet に現われるのに反し後に溶離してくる物はこの homoallyl coupling が結合定数 $1.5 \mathrm{~Hz}$ の triplet に現 われる.この事実より先に浴離してくるるのは 2,4-dimethyl-3-methoxy-2-cyclopentenone (V) であり, 後に溶 離してくるすのは 2,5-dimethyl-3-methoxy-2-cyclopentenone (VI) であると決定した.このような homoallyl couping は先に報告1) した 2-methyl-3-methoxy-4-hydroxy-2-cyclopentenone (VIII) およびその異性体である 2-methyl-3-methoxy-5-hydroxy-2-cyclopentenone (IX) に执いて典型的に見られるすのであるが，これら $2 つ$ は紫外線吸収スペクトル（以下 UV と略す）でIX の方が VIII に比し長波長側にその最大吸収波長を示すが， V, VI の場合もこれと平行な結果を与えた. すなわち IX に相当する VI が VIII に相当する Vよりす1.5 mu. 長波長に最大吸收を示した。この事実からるNMR・より導き出した結論が支持された。<smiles>[R20]C1CCC=C1C</smiles>

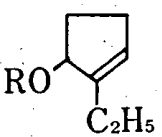

$\mathrm{Xa}, \mathrm{b}$<smiles>COC1=C(C)C(=O)C(C)C1</smiles>

VI

$\mathrm{XIIa}, \mathrm{b}$

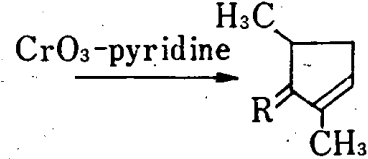

XIII $(\mathrm{VI}) \mathrm{c}, \mathrm{d}$<smiles>COC1=C(C)C(=O)CC1C</smiles><smiles>[R6]C1CC(C)C=C1C</smiles><smiles>[R]C1=C(C)CCC1C</smiles>

$\mathrm{V}$<smiles>[R]C1=C(C)C(C)C(C(C)C)C1</smiles>

XVIc, d<smiles>CO[C@H]1C(C)[C@H](O)[C@@H](O)[C@H]1O</smiles>

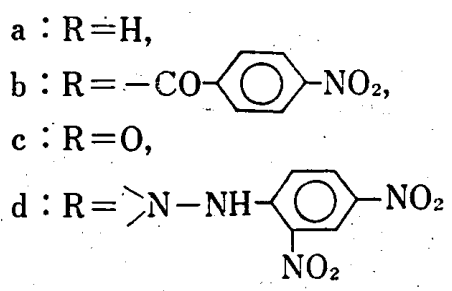

Chart 2

5) C.M. Cimarusti, J. Wolinsky, J. Org. Chem., 31; 4118 (1966); M. Anteunis, F. Compernolle, Bull. Soc. Chim. Belges, 76, 482 (1967). 
つぎにここに得た III-VI 4 種の vinylogous ester の LAH による還元について述へる. 還元条件および後 処理の方法は II を還元した時と同様であった。3) III および IV から得られる壝元生成物はともに GLCで篻一 の peak であり赤外線吸収スペクトル（以下 IR と略す）で水酸基の吸収を示し carbonyl 基による吸収を示さ ない事，また NMR で vinylic proton が 1 個分現われる事より括の拉の相当する allyl alcohol 体, 2-methyl2-cyclopentenol (Xa) および 2-ethyl-2-cyclopentenol (XIa) であると推定し括のおの p-nitrobenzoate (Xb お よび XIb) として確認した.このように II-IV のよ.5な $\alpha$ 位 alkyl 固換基のみを有する 5 員環 vinylogous ester はすべて相当する allyl alcohol に還元され，6 員環のそれらに比し著しく相異することを確認した：

つぎに V および VI.の LAH 還元の結果について述べる.諸条件は III，IV の場合と同様であった。 まず VI の昜合還元生成物は GLC で，III, IV. の場合と同様単一 peak を示し IR で水酸基による吸収を示し carbonyl band を示さない事, NMR で vinylic methyl 1 個と 1 個分の vinylic proton を示すことから. allyl alcohol 体, 2,5-dimethyl-2-cyclopentenol (XIIa) と推定し p-nitrobenzoate (XIIb) として組成を確認した. 今 得られた allyl alcohol 体が 2,4-dimethyl-2-cyclopentenol(XIVa) でないことは XIIaを無水クロム酸ーピリジ ン錯体で酸化することによって文献) 既知の 2,5-dimethyl-2-cyclopentenone $\left(\mathrm{XIII}_{(\mathrm{VI}) \mathrm{c}}\right)^{7}$ としさらにこれを2,4-dinitrophenylhydrazone (XIII(VI)d) に導くことにより確認することができた。

つぎにV の昜合であるが反応処理直後では GLC で 3 つの.peak（以下これらの peak に起因する生成物を 保持特間の短い物より $\mathrm{A}, \mathrm{B}, \mathrm{C}$ とする) を示すが 3 日間室温放置することによって C は B に完全に移行した. この段階でシリカゲルカラムクロマトグラフィーを行ない $\mathrm{A}, \mathrm{B}$ を単離し蒸留し精製した。得られた B は IR で 5 員環 $\alpha, \beta$-unsaturated ketone の吸収を示すことから 2,5-dimethyl-2-cyclopentenone (XIII(V)c) と推定し， GLC でXXIa を酸化して得た XIII (VI)c と同時注入法で一致する事から確認した。また XIII(V)c の 2,4-dinitrophenylhydrazone $\left(\mathrm{XIII}_{(\mathrm{V}) \mathrm{d})}\right.$ は XIII $(\mathrm{VI}) \mathrm{d}$ と融点，IR で完全に一致したまた室温放蒖によって Bに移行し た C は XIII $(\mathrm{V}) \mathrm{c}$ への中間体, 2,4-dimethyl-3-methoxy-2-cyclopentenol (XV) であると推定した.

一方 A はその IR, NMR より 2,4-dimethyl-2-cyclopentenol (XIVa) と推定し $p$-nitrobenzoate (XIVb) と して組成を確認すると共にXIVa を無水クロム酸ーピリジン錯体で酸化することにより文献) 既知の 2,4-(imethyl-2-cyclopentenone (XVIc) としさらにそれを 2,4-dinitrophenylhydrazone (XVId) に導くことによって確 認することができた.XVIc と XIIIcは GLC で明白に保持時間が異っていたまた XVIdと XIIId は融点 にかなりの差があり IR の指紋領域にかなりの相違が見られた。なお V よりの生成物 XIVa $(\mathrm{A}), \mathrm{XIII}(\mathrm{V}) \mathrm{c}(\mathrm{B})$ ， $\mathrm{XV}$ (C) の此率は $71: 13: 16$ であった.

以上のよ5にして III-VI の LAH による還元生成物の構造が明らかになった訳であるがこれらはすべて前 報1)において述べた機構に合致するすのであり，Vよりの結果から $\gamma$ 位に methyl 基があると 5 員環 vinylogous ester に特對的な 1,4 付加がこの methyl 基によって幾分立体的に阻害され 1,2 付加が進行すると考えら れる. 以後置換基効果の著しい alkyl 置換基を $\gamma$ 位あるいは $\delta$ 位に入れ反応を検討していきたい。

\section{実験 の 部}

融点括よび沸点 (浴温) は未補正. TLCには Silica gel G な使用. IR は日本分光 IR-E で，UVは日立 EPS-2 で NMR は日本電子 C-60A で测定. NMR 测定に際しては内部磦準として $\mathrm{Me}_{4} \mathrm{Si}$ を使用。化学シフト は ppm で示し結合定数 $(J)$ は $\mathrm{H}_{\mathrm{z}}$ で示した。な扮分裂の様式には次の略号を用いた。 $\mathrm{s}=$ singlet, $\mathrm{d}=$ doublet, $\mathrm{t}=$ triplet, $\mathrm{q}=$ quartet, $\mathrm{m}=$ multiplet, $\mathrm{br}=$ broad. GLC は Shimazu GC-3AF を用い carrier gas は $\mathrm{N}_{2}(40$ $\mathrm{ml} / \mathrm{min}$ ) を用い,カラム充填版は $5 \%$ SE-30 であった。また NMR における水酸基の signal は $\mathrm{D}_{2} \mathrm{O}$ 添加に より確認した。

LiAlH $_{4}$ 畄元の一般的方法 無水 ether に懸濁した $\mathrm{LiAlH}_{4}$ を筧排，氷冷した所へ vinylogous ester の ether 溶液を滴下する $\left(\mathrm{LiAlH}_{4}\right.$ は理論量の約 10 倍を使用した): 混合物を室温 $3 \mathrm{hr}$ 反応させた後 hydride 1 に対し 6 の割合の $\mathrm{NH}_{4} \mathrm{Cl}$ を加え後水により水冷下 complex を分解し不溶物をろ去したろ液と，不溶物を洗った液と を合し常圧で溶媒留去. GLCで productを分析した，収量はほほ定量的であった。

6) V.A. Mironov, T.M. Fadeeva, G.M. Kuz'yants, A.A. Akhrem, Izv. Akad. Nauk' SSSR, Ser. Khim.2.1966, $2211\left[C . A ., 66,75719_{\mathrm{n}}(1967)\right]$.

7) VIから得られた XIII といら意味で後述するV.から得られた XIII と区別するための表現である。

8) I.N. Nazarov, I.I. Zaretskaya, Zhur. Obshchei. Khim., 27, 624 (1957) [C.A., 51, 16316, (1957)]. 
2-Methyl-3-methoxy-2-cyclopentenone (III) 文献）にしたがって合成した 2-methylcyclopentane-1,3-dione (VIIa) の ether 㲘濁液に過剩の $\mathrm{CH}_{2} \mathrm{~N}_{2}$ etherate を注入し一夜放置後溶媒常圧留去結晶性物賀を $n$-hexane-

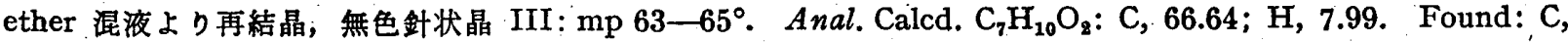
66.37; $\mathrm{H}, 7.76$. IR (Nujol) : $v_{\mathrm{C}=0} 1630 \mathrm{~cm}^{-1}$. NMR $\left(\mathrm{CCl}_{4}\right): 1.54\left(3 \mathrm{H}, \mathrm{t}, J=1.5\right.$, vinylic $\left.\mathrm{CH}_{3}\right), 2.12-2.75(4 \mathrm{H}$, $\left.\mathrm{m}, 2 \times \mathrm{CH}_{2}\right), 3.90\left(3 \mathrm{H}, \mathrm{s}, \mathrm{OCH}_{3}\right)$.

III の LAH 通元生成物 生成物は GLC (カラム温度 $80^{\circ}$ ) でほぼ単一の peakを示した。ミク口蒸留. bp $(3 \mathrm{mmHg})<80^{\circ}$. 2-Methyl-2-cyclopentenol (Xa): IR (film): $\nu_{0 \mathrm{H}} 3320 \mathrm{~cm}^{-1}$. NMR (CDCl $): 1.50-1.90(5 \mathrm{H}$, $\mathrm{m}$, vinylic $\mathrm{CH}_{3}$ と $\left.-\mathrm{CH}_{2}-\mathrm{CH}-\mathrm{OH}\right), 2.05-2.40\left(2 \mathrm{H}, \mathrm{m},=\mathrm{CH}-\mathrm{CH}_{2}-\right), 2.74(1 \mathrm{H}, \mathrm{s},-\mathrm{OH}), 4.57(1 \mathrm{H}, \mathrm{m},>\mathrm{CH}-\mathrm{OH})$, $5.50(1 \mathrm{H}$, br. s, vinylicH).

2-Methyl-2-cyclopentenyl-p-nitrobenzoate $(\mathrm{Xb}) \quad \mathrm{Xa}$ の pyridine 溶液に約 2 倍量の p-nitrobenzoyl chlo-

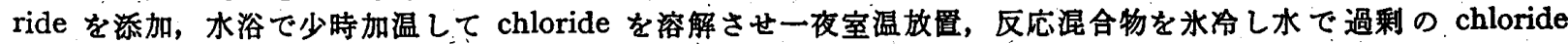
を分解した後，溶媒を減圧下留去，残渣を熱時 ether 抽出 ether 層を $10 \% \mathrm{HCl}, 10 \% \mathrm{Na}_{2} \mathrm{CO}_{3}$, 飽和 $\mathrm{NaCl}$ 水 で洗った後 $\mathrm{MgSO}_{4}$ で乾燥. 溶媒常圧留去.シリカゲルカラムクロマトクラフィーを行ない結晶性物筫を得る. 収 率 70\%。石油エーテルより再結晶. $\mathrm{Xb}: \mathrm{mp} 71$ - $73^{\circ}$. Anal. Calcd. $\mathrm{C}_{13} \mathrm{H}_{13} \mathrm{O}_{4} \mathrm{~N}: \mathrm{C}, 63.15 ; \mathrm{H}, 5.30 ; \mathrm{N}, 5.67$. Found: C, 62.86; H, 5.22; N, 5.96. IR (Nujol) $\mathrm{cm}^{-1}: v_{\mathrm{C}_{x} 0} 1730, \nu_{\mathrm{N}=0} 1535$.

2-Ethyl-3-methoxy-2-cyclopentenone (IV) 文献4,9) の方法によってえた 2-ethylcyclopentane-1,3-dione (VIIb) をIII の場合と同様にメチル化し得られた結晶性牫渣を $n$-hexane より再結晶吸湿性の結晶を得る.IV: $\mathrm{mp} .31-33^{\circ}$. Anal. Calcd. $\mathrm{C}_{8} \mathrm{H}_{12} \mathrm{O}_{2} \cdot 1 / 2 \mathrm{H}_{2} \mathrm{O}: \mathrm{C}, 64.40 ; \mathrm{H}, 8.72$. Found: $\mathrm{C}, 64.21 ; \mathrm{H}, 8.61$. IR (Nujol): $v_{\mathrm{C}=0}$ $1640 \mathrm{~cm}^{-1}$. NMR $\left(\mathrm{CCl}_{4}\right): 0.97\left(3 \mathrm{H}, \mathrm{t}, J=7, \mathrm{CH}_{3}-\mathrm{CH}_{2}-\right), 1.95-2.80\left(6 \mathrm{H}, \mathrm{m},-\mathrm{CH}_{2}-\mathrm{CH}_{3}\right.$ と $\left.-\mathrm{CH}_{2}-\mathrm{CH}_{2}-\right), 3.98$ $\left(3 \mathrm{H}, \mathrm{s}, \mathrm{OCH}_{3}\right)$.

IV の LAH 僄元生成物 生成物は GLC $\left(80^{\circ}\right)$ で単一の peakを示す. ミク口蒸留 bp $(3 \mathrm{mmHg})<80^{\circ} .2-$ Ethyl-2-cyclopentenol (XIa): IR $\left(\mathrm{CHCl}_{3}\right):$ vor $3380 \mathrm{~cm}^{-1}$. NMR $\left(\mathrm{CDCl}_{3}\right): 1.07\left(3 \mathrm{H}, \mathrm{t}, J=7.5,-\mathrm{CH}_{2} \mathrm{CH}_{3}\right), 1.40-$ $2.75\left(6 \mathrm{H}, \mathrm{m},-\mathrm{CH}_{2}-\mathrm{CH}_{3}\right.$ ¿ $\left.-\mathrm{CH}_{2}-\mathrm{CH}_{2}-\right), 2.85(1 \mathrm{H}, \mathrm{s},-\mathrm{OH}), 4.65(1 \mathrm{H}, \mathrm{m},>\mathrm{CH}-\mathrm{OH}), 5.50$ (1 $\mathrm{H}$, br. s, vinylic H).

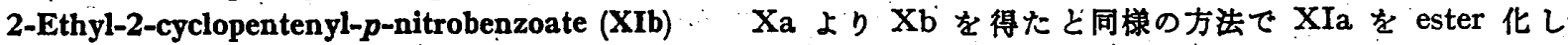
た. 得られる残渣をシリカゲルカラムクロマトクラフィーにかけ得られる粗結晶を石油エーテルより再結晶. 収 率 65\%. XIb: mp 47-49 . Anal. Calcd. $\mathrm{C}_{14} \mathrm{H}_{15} \mathrm{O}_{1} \mathrm{~N}: \mathrm{C}, 64.36 ; \mathrm{H}, 5.79 ; \mathrm{N}, 5.36$. Found: C, 64.12; H, 5.76; $\mathrm{N}, 5.60$. IR (Nujol) $\mathrm{cm}^{-1}: v_{\mathrm{C}=0} 1733$, vNo 1535 .

2,4-Dimethylcyclopentane-1,3-dione (VIIc) 文献10) としたがって ethyl crotonate methylsuccimic acid $13.2 \mathrm{~g}(0.1 \mathrm{~mole})$ を, $40 \mathrm{cc}$ の $\mathrm{CH}_{3} \mathrm{NO}_{2}$ 中に溶解させた $40 \mathrm{~g}(0.3 \mathrm{~mole})$ の $\mathrm{AlCl}_{3}$ 中に徐 々に加え $\mathrm{HCl}$ gas 発生が止まった後 $\mathrm{EtCOCl} 27.6 \mathrm{~g}(0.3 \mathrm{~mole})$ を滴下. 滴下終了後浴温 $80^{\circ}$ と $3 \mathrm{hr}$ 摫汼. 黒色となった反応混合物を氷水中にあけ冷蔵庫に一夜放置，粗結晶 $7 \mathrm{~g}$ を得る。また結晶を除いた後油状物と， 水居を抽出したベンゼンとを合し水で抽出，この水層を濃樎することによってかなり純粋な結晶 $6 \mathrm{~g}$ を得た。得

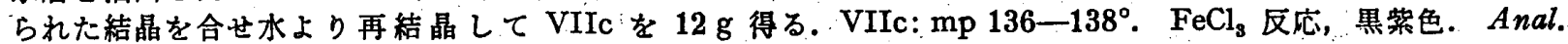
Calç. $\mathrm{C}_{7} \mathrm{H}_{10} \mathrm{O}_{2}: \mathrm{C}, 66, .64 ; \mathrm{H}, 7.99$. Found: $\mathrm{C}, 66.84 ; \mathrm{H}, 7.98$. IR (Nujol) $\mathrm{cm}^{-1}$ : vов 3340, vC=0 1570. NMR $\left(d_{5}\right.$-pyridine $): 1.23\left(3 \mathrm{H}, \mathrm{d}, J=7.5,>\mathrm{CH}_{-} \mathrm{CH}_{3}\right), 1.88\left(3 \mathrm{H}, \mathrm{s}\right.$, vinylic $\left.\mathrm{CH}_{3}\right), 10.88(1 \mathrm{H}, \mathrm{s},-\mathrm{OH})$.

2,4-Dimethyl-3-methoxy-2-cyclopentenone (V) およひ 2,5-Dimethyl-3-methoxy-2-cyclopentenone (VI) 上 に得たVIIc 飞常法通り過剩の $\mathrm{CH}_{2} \mathrm{~N}_{2}$ を働かせ一夜放置後溶媒を常圧留去. 得られる油状物は acetone: $\mathrm{CHCl}_{3}=$ 1:1 を展開溶媒とする TLC では RJ 0.70 の one spot であるがカラム温度 $140^{\circ}$ の GLC では $t_{\mathrm{R}} 6.8 \mathrm{~min}(\mathrm{~V})$ と $t_{\mathrm{R}} 7.8 \mathrm{~min}(\mathrm{VI})$ の two perk であり $\mathrm{V}: \mathrm{VI}=1: 1.14,1.42,1.58$ であうた. 両者はフルミナカラムクロマト グラフィーで展開溶媒を $n$-hexane: ether $(5: 1)$ として根気よく展開することによって分離することができた。こ の場合前半より V が後半より.VI が溶離してきた. V: bp (3 mmHg) $75^{\circ}$. Anal. Calcd. $\mathrm{C}_{8} \mathrm{H}_{12} \mathrm{O}_{2} \cdot 1 / 4 \mathrm{H}_{2} \mathrm{O}: \mathrm{C}$, $66.41 ; \mathrm{H}, 8.71$. Found: $\mathrm{C}, 66.36 ; \mathrm{H}, 8.50$. IR (film) $\mathrm{cm}^{-1}: v_{\mathrm{C}=0} 1620,1680,1730$. UV $\lambda_{\max }^{\operatorname{stog}} \mathrm{m} \mu: 252.0$. NMR $\left(\mathrm{CCl}_{4}\right): 1.18\left(3 \mathrm{H}, \mathrm{d}, J=6,>\mathrm{CH}-\mathrm{CH}_{3}\right), 1.68\left(3 \mathrm{H}, \mathrm{d}, J=1.5\right.$, vinylic $\left.\mathrm{CH}_{3}\right), 4.05\left(3 \mathrm{H}, \mathrm{s}, \mathrm{OCH}_{3}\right)$. VI: bp $(5 \mathrm{mmHg})$ 105. Anal. Calcd. $\mathrm{C}_{8} \mathrm{H}_{12} \mathrm{O}_{2}: \mathrm{C}, 68.54 ; \mathrm{H}, 8.63$. Found: $\mathrm{C}, 68.80 ; \mathrm{H}, 8.74$. IR (film) cm $\mathrm{cm}^{-1}: 1625,1685,1735$. UV $\lambda_{\max }^{\text {Btor }} \mathrm{m} \mu: 253.5$. NMR $\left(\mathrm{CCl}_{4}\right): 1.07\left(3 \mathrm{H}, \mathrm{d}, J=8,>\mathrm{CH}-\mathrm{CH}_{3}\right), 1.50\left(3 \mathrm{H}, \mathrm{t}, J=1.5\right.$, vinylic $\left.\mathrm{CH}_{\mathrm{s}}\right), 3.93(3 \mathrm{H}$, $\mathrm{s}, \mathrm{OCH}_{3}$ ).

VI の LAH 逗元生成物 油状の生成物は GLC (カラム温度 $80^{\circ}$ ) で単一の peakを与方 $\left(t_{\mathrm{R}}: 4 \mathrm{~min}\right)$ TLC $\left(\mathrm{CHCl}_{3}\right)$ Rf 0.40. 2,5-Dimethyl-2-cyclopentenol (XIIa). bp (10 mmHg) 80 -90.. IR $\left(\mathrm{CHCl}_{3}\right): v_{\mathrm{OH}} 3380$ $\mathrm{cm}^{-1}$. NMR $\left(\mathrm{CDCl}_{3}\right): 1.02\left(3 \mathrm{H}, \mathrm{m},>\mathrm{CH}-\mathrm{CH}_{3}\right), 1.73\left(3 \mathrm{H}\right.$, nearly s, vinylic $\left.\mathrm{CH}_{3}\right), 2.38(1 \mathrm{H}, \mathrm{s},-\mathrm{OH}), 3.80-4.60$ $(1 \mathrm{H}, \mathrm{m},>\mathrm{CH}-\mathrm{OH}), 5.43(1 \mathrm{H}, \mathrm{br}, \mathrm{s}$, vinylic $\mathrm{H})$.

2,5-Dimethyl-2-cyclopentenyl-p-nitrobenzoate (XIIb) 上に得た XIIa を常法通りp-nitrobenzoate とした。

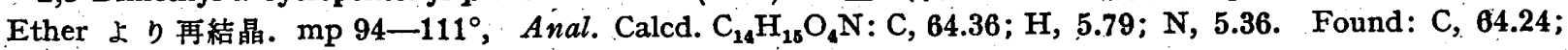

9) J.M. Nilsson, F. Merenyi, Fr. Patent 1403810 (1965) [C.A., 63, 17931 (1965)]; H. Smith, Brit. Patent 1051836 (1966) [C.A., 66, 55104e (1967)].

10) G.B. Brown, "Org. Syn," Vol. 26, Johnwiley and Sons, Inc., Neww York, N.Y., 1946, p. 54. 
$\mathrm{H}, 5.81 ; \mathrm{N}, 5.49$. IR (Nujol) $\mathrm{cm}^{-1}: \nu_{\mathrm{C}=0} 1730,1710, \nu_{\mathrm{N}=0} 1530$. NMR $\left(\mathrm{CCl}_{4}\right): 0.90-1.35\left(3 \mathrm{H}, \mathrm{m},>\mathrm{CH}-\mathrm{CH}_{3}\right)$, 1.75 (3H, br. s, vinylic $\mathrm{CH}_{3}$ ), 5.50, 5.68 (各 $1 \mathrm{H}, \mathrm{m},>\mathrm{CH}-\mathrm{O}$ 之 vinylic $\mathrm{H}$ ), 8.23 (4H, s, aromatic $\mathrm{H}$ ).

XIIa の $\mathrm{CrO}_{3}$-pyridine による酸化 XIIaを pyridine に溶解させておきこれに過剩の無水 $\mathrm{CrO}_{3}$-pyridine

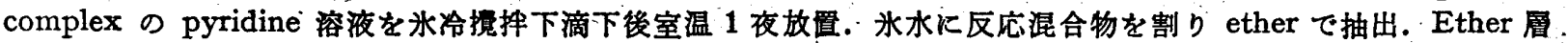
を $10 \% \mathrm{HCl}$ ついで飽和 $\mathrm{NaCl}$ 水で洗い $\mathrm{MgSO}_{4}$ で乾燥. 溶媒常压濃樎. GLC $\left(80^{\circ}\right): t_{\mathrm{R}} 5.3 \mathrm{~min}$. 浱樎した ether 溶液に 2,4-dinitrophenylhydrazine 試液を加え得られる結晶を EtOH から再結晶. XIII(vI)d: 赤色針状 結晶, $\mathrm{mp} 196-197^{\circ}$ (文献) 值 $194.5-196^{\circ}$ ). Anal. Calcd. $\mathrm{C}_{18} \mathrm{H}_{14} \mathrm{O}_{4} \mathrm{~N}_{4}: \mathrm{C}, 53.79 ; \mathrm{H}, 4.86 ; \mathrm{N}, 19.30$. Found: C, $53.62 ; \mathrm{H}, 4.93 ; \mathrm{N}, 19.12$.

Vの LAH 通元生成物 油状の生成物は GLC (80) の面積強度比で 71(2,4-dimethyl-2-cyclopentenol, $\left.\mathrm{XIVa}, t_{\mathrm{R}} 4.3 \mathrm{~min}\right): 13$ (2,5-dimethyl-2-cyclopentenone, $\left.\mathrm{XIII}(\mathrm{V}) \mathrm{c}, t_{\mathrm{R}} 5.3 \mathrm{~min}\right): 16$ (2, 4-dimethyl-3-methoxy-2cyclopentenol, XVI, $\left.t_{\mathrm{R}} 6.3 \mathrm{~min}\right)$ の 3 つの peak を示し 3 日間室温放置しておくと XVI に移行する.この時点での TLC $\left(\mathrm{CHCl}_{3}\right)$ は Rf 0.40 (XIVa), 0.81 (XIII (V)e $)$ であった.シリカケルカラムクロ マトグラフィーを行ない両者を単離しおのおのミクロ蒸留を行なった。 bp $\left.(10 \mathrm{mmHg})<80^{\circ} \mathrm{XIV}_{\mathrm{a}}: \mathrm{IR}_{(\mathrm{CHCl}}\right)$ : $\nu_{\mathrm{OH}} 3420 \mathrm{~cm}^{-1}$. NMR $\left(\mathrm{CDCl}_{3}\right): 1.03\left(3 \mathrm{H}, \mathrm{m},>\mathrm{CH}-\mathrm{CH}_{3}\right), 1.78\left(3 \mathrm{H}, \mathrm{br} . \mathrm{s}\right.$, vinylic $\left.\mathrm{CH}_{3}\right), 4.40(1 \mathrm{H}, \mathrm{br},>\mathrm{CH}-\mathrm{OH})$, $5.48(1 \mathrm{H}, \mathrm{m}$, vinylic $\mathrm{H})$. XIII $(\mathrm{V}) \mathrm{c}$ : IR $\left(\mathrm{CHCl}_{3}\right): \nu_{\mathrm{C}=0} 1694 \mathrm{~cm}^{-1}$. XIII $(\mathrm{v}) \mathrm{c}$ は GLC の同時注入法で XIII $(\mathrm{VI}) \mathrm{c}$ と完全に一致した.

2,4-Dimethyl-2-cyelopentenyl-p-nitrobenzoate (XIVb) 上に得た XIVa を常法通り ester 化した. bp (0.4 mmHg) $135^{\circ}$ ，非晶体. Anal. Calcd. $\mathrm{C}_{14} \mathrm{H}_{15} \mathrm{O}_{4} \mathrm{~N}: \mathrm{C}, 64.36 ; \mathrm{H}, 5.79 ; \mathrm{N}, 5.36$. Found: C, 64.47; $\mathrm{H}, 5.91 ; \cdot \mathrm{N}$, 5.44. IR (film) $\mathrm{cm}^{-1}: v_{\mathrm{C}=0} 1722$, vNo 1530. NMR $\left(\mathrm{CCl}_{4}\right): 1.10,1.13$ (おのおの d, $\left.J=6.5,>\mathrm{CH}_{-} \mathrm{CH}_{3}\right), 1.78(3 \mathrm{H}$, $\mathrm{s}$, vinylic $\left.\mathrm{CH}_{3}\right), 5.67,5.83$ (各 $1 \mathrm{H}, \mathrm{m},>\mathrm{CH}-\mathrm{O}$ \& vinylic $\mathrm{H}$ ), $8.26(4 \mathrm{H}$, s, aromatic $\mathrm{H})$.

2,5-Dimethyl-2-cyclopentenone-2,4-dinitrophenylhydrazone (XIII(v)d) XIII(v)c の EtOH 液に 2,4-dinitrophenylhydrazine 試液を加え一夜放固，析出した結晶を EtOH から再結晶.”赤色針状結晶。 mp 196一198。

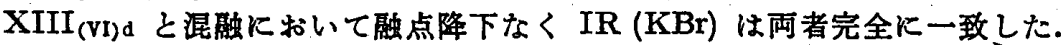

XIVa の $\mathrm{CrO}_{3}$-Pyridine による酸化 XIIa: の場合と同様に酸化じ ether 常圧源縮. GLC $\left(80^{\circ}\right) t_{\mathrm{R}} 5.6 \mathrm{~min}$. XIIIc とは GLCの同時注入法で明らかに異なることを確認. 2,4-Dinitrophenylhydrazine 圾液を加えさらにether を濃樎すると結晶が析出. EtOH から再結晶. 2,4-Dimethyl-2-cyclopentenone-2,4-dinitrophenylhydrazone

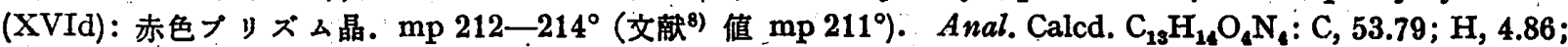
$\mathrm{N}, 19.30$. Found: $\mathrm{C}, 53.73 ; \mathrm{H}, 5.05 ; \mathrm{N}, 19.24$. IR (KBr) では XIIId と指紋領域においてかなりの相異が見 られた。

棓辞 終りに臨み゙ NMR を測定して下さいました当学部 森腰正弘氏，元素分析を担当して下さいました本 学部高見春男氏に感謝致します。 